\title{
TU/e EmonOWEN

\section{Thermodynamic and kinetic study of diffusion paths in the system Cu-Fe-Ni}

\section{Citation for published version (APA):}

Rönkä, K. J., Kodentsov, A., Loon, van, P. J. J., Kivilahti, J., \& Loo, van, F. J. J. (1996). Thermodynamic and kinetic study of diffusion paths in the system Cu-Fe-Ni. Metallurgical and Materials Transactions A: Physical Metallurgy and Materials Science, 27(8), 2229-2238. https://doi.org/10.1007/BF02651877

DOI:

10.1007/BF02651877

Document status and date:

Published: 01/01/1996

\section{Document Version:}

Publisher's PDF, also known as Version of Record (includes final page, issue and volume numbers)

\section{Please check the document version of this publication:}

- A submitted manuscript is the version of the article upon submission and before peer-review. There can be important differences between the submitted version and the official published version of record. People interested in the research are advised to contact the author for the final version of the publication, or visit the $\mathrm{DOI}$ to the publisher's website.

- The final author version and the galley proof are versions of the publication after peer review.

- The final published version features the final layout of the paper including the volume, issue and page numbers.

Link to publication

\section{General rights}

Copyright and moral rights for the publications made accessible in the public portal are retained by the authors and/or other copyright owners and it is a condition of accessing publications that users recognise and abide by the legal requirements associated with these rights.

- Users may download and print one copy of any publication from the public portal for the purpose of private study or research.

- You may not further distribute the material or use it for any profit-making activity or commercial gain

- You may freely distribute the URL identifying the publication in the public portal.

If the publication is distributed under the terms of Article 25fa of the Dutch Copyright Act, indicated by the "Taverne" license above, please follow below link for the End User Agreement:

www.tue.nl/taverne

Take down policy

If you believe that this document breaches copyright please contact us at:

openaccess@tue.nl

providing details and we will investigate your claim. 


\title{
Thermodynamic and Kinetic Study of Diffusion Paths in the System $\mathrm{Cu}-\mathrm{Fe}-\mathrm{Ni}$
}

\author{
K.J. RÖNKÄ, A.A. KODENTSOV, P.J.J. VAN LOON, J.K. KIVILAHTI, and F.J.J. VAN LOO
}

(1)

matis

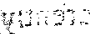

2

ato

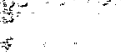

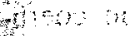

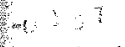

$(n+2)$

ent:

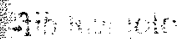

ADVANCED materials are of increasing importance in modern technology. For the most part; these are complex multicomponent and multiphase materiais such as composites or hybrid structures; which require various types of microjoining and bonding operations. Joinability and compatibility of dissimilar materials largely determine the properties and functionability of these multimaterial assemblies. For mass production soldering, brazing or diffusion bonding are frequently employed methods of joining. New applications of advanced materials require the development of joining materials and processes. This can be carried out effectively by first achieving a better understanding and so controlling the interfacial reactions and diffusion processes. In this respect, thermodynamics and a diffusion-kinetic approach combined with detailed microanalysis techniques can be of great help.

Diffusion and chemical reactions at the interfaces play an essential role in bonding as well as in the mechanical, physical -and chemical performance of the joints. It is noteWorthy that these time-dependent structural changes are not anly observed in the joining process but are also important during storage and in the use of bonded structures. This is of particular importance in soldering, since the operation temperatures are relatively close to the melting points of conventional solder fillers, and therefore, diffusion is still remarkably fast.

For practical purposes, it is advantageous to develop a model for predicting possible diffusion paths in the joint area. However, in multicomponent systems, the existence of a liquid phase and grain boundary diffusion, as well as

K.J. RÖNKÄ, Postdoctoral Student, and J.K. KIVILAHTI, Prôfessor, are with the Department of Materials Science and Engineering, Helsinki Uiviversity" of Technology, 02150 Espoo, Finland. A.A. KODENTSOV, Researcher, and F.J.J. VAN LOO, Professor, Laboratory of Solid State Chemistry and Materials Science, and P.J.J. VAN LOON, Undergraduate Student, Department of Chemical Engineering, are with Eindhoven University of Technology, $5600 \mathrm{MB}$ Eindhoven, The Netherlands. Manuscript submitted November 11, 1994. the lack of data on mobility or thermodynamic data, makes a reliable prediction of actual diffusion paths very difficult. Therefore, the relatively simple $\mathrm{Cu}-\mathrm{Fe}-\mathrm{Ni}$ system was chosen in this article to study the diffusion in two-phase systems. Results of this model system will be subsequently applied to more complex systems such as $\mathrm{Cu}-\mathrm{Ag}-\mathrm{Sn}$, Cu$\mathrm{Ag}-\mathrm{Zn}$, and $\mathrm{Cu}-\mathrm{Sn}-\mathrm{Zn}$, which are of great interest for brazing and soldering applications. Furthermore, the $\mathrm{Cu}-\mathrm{Fe}-\mathrm{Ni}$ system has the advantage of a wide range of compositions that can be chosen as starting materials in the diffusion couples, and moreover, thermodynamic and kinetic data are fairly well known. It is emphasized, however, that despite their thermodynamic simplicity, the solid solutions of the $\mathrm{Cu}-\mathrm{Fe}-\mathrm{Ni}$ system are not ideal.

The recent development of thermodynamic computer software and data banks provides a much better basis for avoiding the assumption of ideal behavior of solid solutions used commonly in diffusion analysis. Knowing the activities of components as a function of composition and temperature, it is possible to use the gradients of chemical potentials as driving forces for diffusion. This also allows the derivation of intrinsic diffusion properties if the atomic mobilities of each component are available as a function of composition.

\section{THEORETICAL BACKGROUND}

The limited amount of study in multicomponent systems is, first, due to a lack of reliable analytical and numerical methods for the calculation of interdiffusion, intrinsic diffusion, and tracer diffusion coefficients and their concentration dependence, and second, due to a lack of thermodynamic data:

Analytical methods for calculating diffusion paths anid other diffusion properties can be used only when the intêdiffusion coefficients are assumed to be constants. Many equations and solutions available in the literature based on the use of error functions. The assumption of constant interdiffusion coefficients is reasonable in diffusision couples with a relatively small composition difference be- 
tween the terminal alloys. Solutions based on error functions produce symmetric concentration profiles on both sides of the Matano plane unless modified mathematical models are used, for example, as done by van Loo et al. ${ }^{[6]}$ and Thompson and Morral ${ }^{[7,8]}$ Therefore, numerical methods are needed, in most cases, to describe the diffusion properties in diffusion couples with concentration-dependent diffusion coefficients and/or large concentration differences. For reliable calculations, the thermodynamic assessment of the system and the concentration dependence of the tracer diffusion coefficients in each phase have to be known. ${ }^{[9]}$ Other types of approaches such as the atomistic treatment based on the path probability method by Sato ${ }^{[10]}$ or studies based on "zero-flux planes," have also been suggested.

One problem in multicomponent diffusion is the prediction of the diffusion path between the two terminal alloys: By definition, the diffusion path is a line from one terminal alloy to another on the ternary isotherm, corresponding to the locus of the average composition in planes parallel to the original interface throughout the diffusion zone. The diffusion path is dependent on the gradient of chemical potentials and the mobilities of each component, taking into account the mass-balance requirement. If the mobilities of all components are nearly equal and concentration independent, the effect of the thermodynamic driving forces dominates the course of the diffusion path.

The diffusion path reflects the morphology of the diffusion area: If phases are separated by planar interfaces, the diffusion path crosses the two-phase region along a tie-line, and along the entire interface, the same local equilibrium can be assumed. This is not necessarily the case: regions of supersaturation can be formed near the interface. This implies an interface which is thermodynamically unstable, developing wavy interfaces or isolated precipitates. The diffusion path then crosses the tie-lines in the two-phase area. These unstable interfaces can be described by the "virtual paths" suggested by Kirkaldy and Brown. ${ }^{[12]}$ Rapp et al: ${ }^{[13]}$ used a simple model to predict whether, in displacementtype diffusion couples, single-phase layers separated by planar interfaces or two-phase product layers will be formed.

Van Loo ét al. ${ }^{[14]}$ have shown that it is possible to predict qualitatively the layer sequence and morphology in diffusion couples by using kinetic and thermodynamic data on a ternary system. The basic assumption is that no element can diffuse intrinsically against its own activity gradient: If a maximum is found experimentally in the activity profile of a component, this is caused by the intrinsic movement of the other two components.

For reliable diffusion analyses as well as for predictive calculations, data for the interdiffusion, intrinsic diffusion, and/or tracer diffusion coefficients and their concentration dependence have to be known. In ternary systems, the four relevant interdiffusion coefficients and six intrinsic diffusion coefficients have different values dependent on which component is taken as the dependent concentration variable. The tracer diffusion coefficients, in this sense, are preferable. Besides, thermodynamic data for the system have to be known for the calculation of the chemical potentials of each component as a function of composition at constant temperature and pressure. In this section, a method for calculating the three tracer diffusion coefficients in a substitutional ternary system at the intersection points of two diffusion paths is presented.
Kirkaldy ${ }^{[15]}$ has demonstrated the extension of the Boltzmann-Matano analysis to multicomponent systems. In the ternary case, the four relevant interdiffusion coefficients can be calculated from two independent diffusion couples which have one point with a common composition. This method was first used by Ziebold and Ogilvie in the $\mathrm{Cu}$ $\mathrm{Au}-\mathrm{Ag}$ system. ${ }^{[2]}$ In order to get information about the concentration dependence of the interdiffusion coefficients, numerous diffusion couples have to be studied. In multicomponent systems with $n \geq 4$, this method is apparently useless because of the enormous amount of experiments required ${ }^{[16]}$ Data on interdiffusion coefficients and diffusion paths can be found on several ternary systems, as reviewed recently by Dayananda. ${ }^{[17]}$

The determination of the six intrinsic diffusion coefficients, $D_{i j p}^{\prime}$, has been presented by Lane and Kirkaldy. ${ }^{[18]}$ In the literature, such studies are limited to the cases Fe-Co-

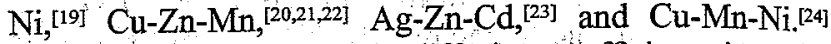
The calculation of intrinsic diffusion coefficients in nonideal and concentrated multicomponent systems has been limited by a lack of reliable thermodynamic data.

In a ternary system, the Onsager's phenomenological diffusion coefficients form an $L(3 \times 3)$ matrix. ${ }^{[25]}$ Since it is reasonable to assume that in substitutional alloys the metal atoms diffuse only by exchange with the neighboring vacancies, the frequency of direct atom interchanges is small compared with atom-vacancy interchanges. ${ }^{[26,27]}$ If vacancies are in equilibrium in the system and the contributions of vacancy wind and correlation effects are neglected, it is possible to eliminate the nondiagonal elements in the $L_{i j}$ matrix. Related to the Kirkendall frame of reference, the intrinsic diffusion fluxes $J_{i}\left(\mathrm{~mol} \mathrm{~cm} \mathrm{~cm}^{-2} \mathrm{~s}^{-1}\right)$ can then be written as $^{[1]}$

$$
\begin{aligned}
& J_{1}=-L_{11} \frac{\partial \mu_{1}}{\partial x}=-D_{11} \frac{\partial c_{1}}{\partial x}-D_{12} \frac{\partial c_{2}}{\partial x} \\
& J_{2}=-L_{22} \frac{\partial \mu_{2}}{\partial x}=-D_{21} \frac{\partial c_{1}}{\partial x}-D_{22} \frac{\partial c_{2}}{\partial x} \\
& J_{3}=-L_{33} \frac{\partial \mu_{3}}{\partial x}=-D_{31} \frac{\partial c_{1}}{\partial x}-D_{32} \frac{\partial c_{2}}{\partial x}
\end{aligned}
$$

where $c_{i}$ is the concentration $(\mathrm{mol} \mathrm{cm}-3), x$ the distance parameter $(\mathrm{cm}), \mu_{i}$ the chemical potential $\left(\mathrm{J} \cdot \mathrm{mol}^{-1}\right)$, and $D_{i j}$ the intrinsic diffusion coefficient $\left(\mathrm{cm}^{2} \mathrm{~s}^{-1}\right)$. For the relation between phenomenological diffusion coefficients $L_{i j}$ and tracer diffusion coefficients $D_{i}^{*}$, Darken ${ }^{[28]}$ and LeClaire ${ }^{[27]}$ have derived the equation

$$
L_{i i}=\frac{c_{i} D_{i}^{*}}{\mathrm{R} T}
$$

This leads to

$$
J_{i}=-\frac{c_{i} D_{i}^{*}}{\mathrm{R} T} \frac{\partial \mu_{i}}{\partial x}=-\frac{N_{i} D_{i}^{*}}{\mathrm{R} T V^{m}} \frac{\partial \mu_{i}}{\partial x}
$$

where $N_{i}$ is the atomic fraction of component $i$ and $V^{m}$ is the molar volume $\left(\mathrm{cm}^{3} / \mathrm{mole}\right.$ of atoms), assumed to be constant in this analysis. The activity $a_{i}$ is related to the chemical potential, $\mu_{i}$, through the equation

$$
\mu_{i}=\mu_{i}^{o}+\mathrm{R} T \ln a_{i}
$$

which leads to 


$$
J_{i}=\frac{D_{i}^{*}}{V^{m}} \frac{N_{i}}{a_{i}} \frac{\partial a_{i}}{\partial x}=-\frac{D_{i}^{*}}{V^{m}} \frac{1}{\gamma_{i}} \frac{\partial a_{i}}{\partial x}
$$

where $\gamma_{i}=a_{i} / N_{i}$ is the activity coefficient of component $i$. The relationship between the interdiffusion fluxes, $\tilde{J}_{i}$, and the intrinsic diffusion fluxes, $J_{i}$, is given by ${ }^{[6]}$

$$
\tilde{J}_{i}=J_{i}-N_{i} \sum_{j=1}^{3} J_{j}
$$

The interdiffusion fluxes related to the Matano plane can be derived as a function of interdiffusion coefficients, $D_{i j}^{n}$, and concentration gradients or as a function of tracer diffusion coefficients and chemical potential gradients as follows:

$$
\begin{gathered}
\tilde{J}_{1}=-\frac{\tilde{D}_{11}^{3}}{V^{m}} \frac{\partial N_{1}}{\partial x}-\frac{\tilde{D}_{12}^{3}}{V^{m}} \frac{\partial N_{2}}{\partial x} \\
\tilde{J}_{2}=-\frac{\tilde{D}_{21}^{3} \frac{\partial N_{1}}{V^{m}}-\frac{\tilde{D}_{22}^{3}}{\partial x} \frac{\partial N_{2}}{\partial x}}{V^{m}} \quad \tilde{J}_{3}=-\tilde{J}_{1}-\tilde{J}_{2}
\end{gathered}
$$

or (through Eqs., [3] and [6])

$$
\begin{aligned}
& \tilde{J}_{1}=-\frac{N_{1} D_{1}^{*}}{R V^{m}} \frac{\partial \mu_{1}}{\partial x}+N_{1}^{*}\left(\frac{N_{1} D_{1}^{*}}{R T V^{m}} \frac{\partial \mu_{1}}{\partial x}+\frac{N_{2} D_{2}^{*}}{R T V^{m}} \frac{\partial \mu_{2}}{\partial x}+\frac{N_{3} D_{3}^{*}}{R T V^{m}} \frac{\partial \mu_{3}}{\partial x}\right) \\
& \tilde{J}_{2}=-\frac{N_{2} D_{2}^{*}}{R V^{m}} \frac{\partial \mu_{2}}{\partial x}+N_{2}\left(\frac{N_{1} D_{1}^{*}}{R T V^{m}} \frac{\partial \mu_{1}}{\partial x}+\frac{N_{2} D_{2}^{*}}{R T V^{m}} \frac{\partial \mu_{2}}{\partial x}+\frac{N_{3} D_{3}^{*}}{R T V^{m}} \frac{\partial \mu_{3}}{\partial x}\right) \\
& \tilde{J}_{3}^{*}=\tilde{J}_{I}^{*} J_{2}
\end{aligned}
$$

Using the Matano-Boltzmann analysis for the multicomponent system, ${ }^{15}, 291$ the interdiffusion fluxes can be calculated from the experimental diffusion profile

$$
\tilde{J}_{i}=\frac{1}{2 t V^{m}} \int_{N_{i}\left(T_{(}^{\infty}\right)}^{N_{i}^{t}} x d N_{i}
$$

where the origin $(x=0)$ coincides with the Matano inter-

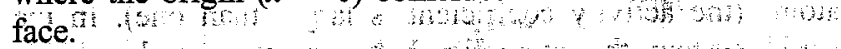
When the tracer diffusion coefficients are known, the vacancy flux can be calculated from the equation

$J_{\nu}=\sum_{j=1}^{3} J_{j}=\frac{N_{1} D_{1}^{*}}{\mathrm{R} T^{m}} \frac{\partial \mu_{1}}{\partial x}+\frac{N_{2} D_{2}^{*}}{R T V^{m}} \frac{\partial \mu_{2}}{\partial x}+\frac{N_{3} D_{3}^{*}}{R T V^{m}} \frac{\partial \mu_{3}}{\partial x}$

st At the original (Kirkendall) plane, the vacancy flux is related to the marker shift, $\Delta x_{m}$, by the relation

$$
\text { if } \frac{\Delta x_{m}}{2 t}=V_{m}^{m} J_{v}
$$

: Using thermodynamic data, an experimental composition profile can be converted to a profile of activity or chemical potential At an intersection point of two inde pendent diffusion profiles; the values for the interdiffusion fluxes in $\mathrm{Eq}-[9]$ can be obtained and the four interdiffusion coefficients in Eq [7] or the three tracer diffusion coefficients in Eq. [8] can be calculated. If one component has an extremum in its activity profile, one term in Eq. [8] can be neglected and two tracer diffusion coefficients can be calculated at this point from a single diffusion profile.

In all analyses, one has to remember that $\sum_{i} N_{i}=1, \sum_{i} \tilde{J}_{i}$ $=0$, and $\sum_{i} N_{i} d \mu_{i}=0$ (Gibbs-Duhem), which means that according to Eq. [3], $\sum_{i} \frac{J_{i}}{D_{i}^{*}}=0 .{ }^{[21]}$

If experimentally determined concentration-penetration $\left(N_{i}-x\right)$ curves are converted into $\left(\mu_{i}-x\right)$ or $\left(a_{i}-x\right)$ curves, it is possible that the extrema in these curves will be found. Applying Eq. [1] to these curves will give rise to intrinsic fluxes, $J_{i}$, which are positive on one side and negative on the other side of this extremum. On the other hand, van Loo ${ }^{[6]}$ used another concept in which he introduced "intrinsic" diffusion fluxes, $J_{i}$, which are independent of each other and always directed from higher activity of a component in one end member to lower activity in the other end member. Extrema in the activity. curves of one component are then caused by the interaction with the intrinsic fluxes, $J_{j}$, of the other components, which are also only positive or only negative. This definition was used for predictions of diffusion curves from known tracer diffusion coefficients in thermodynamically ideal systems, but it is less useful in our case in which an experimental curve has to be used to calculate these diffusion coefficients. Therefore, we will further use the dependent intrinsic fluxes, $J_{i}$ (without prime), as defined in Eq. [1], with the knowledge now that these fluxes in principle, can change sign because of the occurrence of extrema. The relation between these two flux definitions is presented in the Appendix.

In the ternary $\mathrm{Cu}-\mathrm{Fe}-\mathrm{Ni}$ system, the effects of volume changes due to mixing are negligible ${ }^{[30]}$ and a constant av erage value for the molar volume $\left(V^{m}=6.9 \mathrm{~cm}^{3} / \mathrm{mole}\right.$ of atoms) can be used. The grain size is large enough (average about $100 \mu \mathrm{m}$ ) to eliminate the effect of grain boundary diffusion in the entire diffusion zone.

\section{EXPERIMENTAL PROCEDURE}

Copper ( 99.99 pct purity), iron (99.98 pct), and nickel $(99.98$ pct) supplied by Goodfellow, (Cambridge, United Kingdom) were used as initial materials. A number of binary $(\mathrm{Cu}-\mathrm{Ni}, \mathrm{Fe}-\mathrm{Ni}$, and $\mathrm{Fe}-\mathrm{Cu})$ and ternary $(\mathrm{Cu}-\mathrm{Fe}-\mathrm{Ni})$ alloys were prepared in an arc furnace under argon using a nonconsumable tungsten electrode. The ingots were remelted five times to improve their homogeneity. The spec: imens were annealed in an electroresistance furnace in evacuated quartz ampoules at $1000{ }^{\circ} \mathrm{C}$ for 250 to 530 hours and quenched in water.

The diffusion couples were prepared and heat treated in a vacuum furnace $\left(5^{*} 10^{-6} \mathrm{mbar}\right)$ under an external load of $2 \mathrm{MPa}$. After annealing and standard metallographic preparation, the diffusion couples and equilibrium alloys were examined with light microscopy, scanning electron micros; copy, and electron probe microanalysis. Small particles $(0.5$ $\mu \mathrm{m})$ of hafnium dioxide or aluminum oxide were used as inert markers between the initial materials prior to heat treat ment. 
Table I. Compositions (in Atomic Percent) of Ternary Alloys Annealed at $1000{ }^{\circ} \mathrm{C}$ for 530 Hours

\begin{tabular}{|c|c|c|c|}
\hline Alloy & Initial & Phase 1 & Phase 2 \\
\hline 1 & $50 \mathrm{Cu}-40 \mathrm{Fe}-10 \mathrm{Ni}$ & $9 \mathrm{Cu}-76 \mathrm{Fe}-15 \mathrm{Ni}$ & $91 \mathrm{Cu}-5 \mathrm{Fe}-4 \mathrm{Ni}$ \\
\hline 2 & $55 \mathrm{Cu}-25 \mathrm{Fe}-20 \mathrm{Ni}$ & $20 \mathrm{Cu}-48 \mathrm{Fe}-32 \mathrm{Ni}$ & $79 \mathrm{Cu}-$ \\
\hline 3 & $53 \mathrm{Cu}-21 \mathrm{Fe}-26 \mathrm{Ni}$ & $36 \mathrm{Cu}-31 \mathrm{Fe}-33 \mathrm{Ni}$ & $66 \mathrm{Cu}-14 \mathrm{Fe}-20 \mathrm{Ni}$ \\
\hline 4 & $55 \mathrm{Cu}-15 \mathrm{Fe}-30 \mathrm{Ni}$ & \multirow{3}{*}{\multicolumn{2}{|c|}{ single phase }} \\
\hline 5 & $55 \mathrm{Cu}-12 \mathrm{Fe}-33 \mathrm{Ni}$ & & \\
\hline 6 & $39 \mathrm{Cu}-20 \mathrm{Fe}-41 \mathrm{Ni}$ & & \\
\hline
\end{tabular}

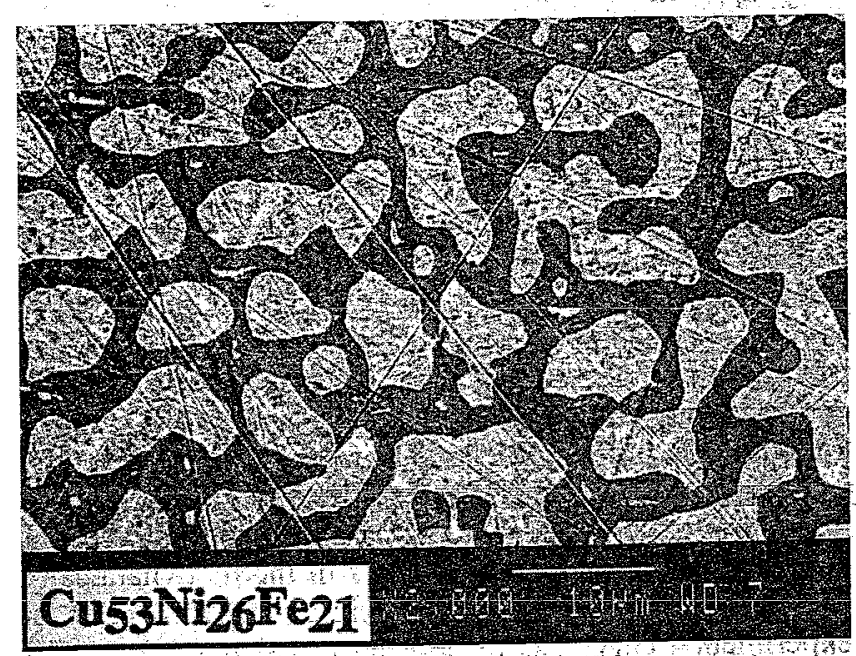

(a)

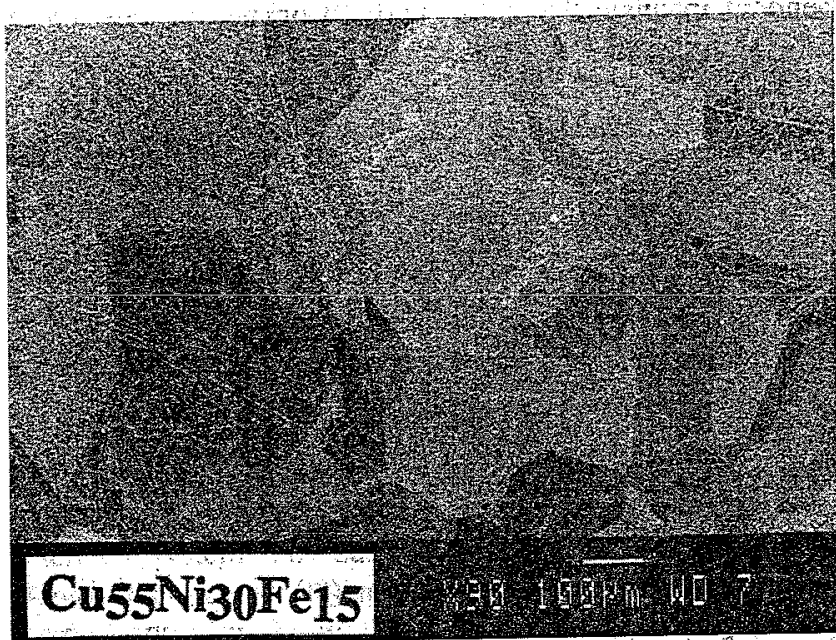

(b)

tais

Fig. 1-Backscattered electron images of some ternary $\mathrm{Cu}-\mathrm{Fe}-\mathrm{Ni}$ alloys after annealing at $1000^{\circ} \mathrm{C}$ for $530 \mathrm{~h}$ and quenching. (a) Alloy $53 \mathrm{Cu}-21 \mathrm{Fe}-$ $26 \mathrm{Ni}$ consists of two phases: $36 \mathrm{Cu}-31 \mathrm{Fe}-33 \mathrm{Ni}$ with därk contrast and $66 \mathrm{Cu}-14 \mathrm{Fe}-20 \mathrm{Ni}$ with light contrast. (b) Alloy $55 \mathrm{Cu}-15 \mathrm{Fe}-30 \mathrm{Ni}$ shows the single-phase structure.

\section{RESULTS AND DISCUSSION}

\section{A. Miscibility Gap in the Cu-Fe-Ni System at $1000^{\circ} \mathrm{C}$}

Results of the investigation of equilibrated ternary $\mathrm{Cu}-$ $\mathrm{Fe}-\mathrm{Ni}$ alloys are summarized in Table $\mathrm{I}$. The alloy of composition $53 \mathrm{Cu}-21 \mathrm{Fe}-26 \mathrm{Ni}$ (at. pct) still lies inside the miscibility gap at $1000^{\circ} \mathrm{C}$. This is revealed by the twophase microstructure of this alloy after heat treatment and quenching in water (Figure 1(a)). On the contrary, the alloy of composition $55 \mathrm{Cu}-15 \mathrm{Fe}-30 \mathrm{Ni}$ shows the one-phase mi-

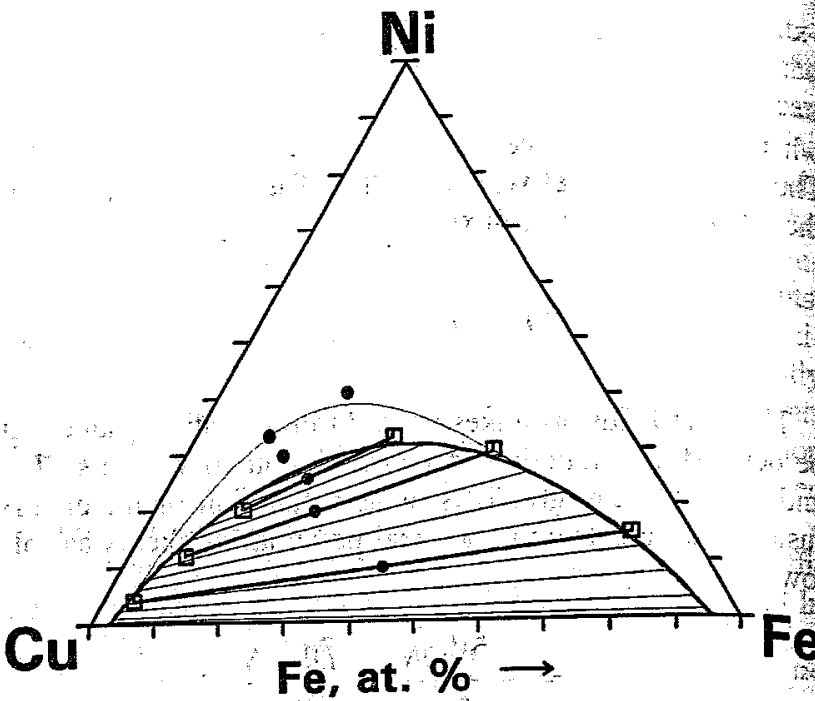

Fig. 2-The miscibility gap in the $\mathrm{Cu}-\mathrm{Fe}-\mathrm{Ni}$-system at $1000^{\circ} \mathrm{C}$ based on the experimental results and the thermodynamic reassessment in the present work (the solid curve) compared with the original assessment ${ }^{31}$ (dashed curve). The nominal compositions of the initial alloys $(\bullet)$ are given in Table $\mathrm{I}$.

crostructure after annealing at the same condition and quenching (Figure 1(b)). Based on electron microprobe analysis of the phases in the alloys, the direction of the tielines within the two-phase region and the boundary of the miscibility gap in the $\mathrm{Cu}-\mathrm{Fe}-\mathrm{Ni}$ system at $1000^{\circ} \mathrm{C}$ were established (Figure 2).

The thermodynamic calculations on the $\mathrm{Cu}-\mathrm{Fe}-\mathrm{Ni}$ system at $1000{ }^{\circ} \mathrm{C}$ are based on the critical assessment of Jansson. ${ }^{[31]}$ In this evaluation, Jansson has used experimentally determined activities in the binary as well as in the ternary systems at $1000^{\circ} \mathrm{Cn}$ the basis of our new experimental solubility results, the ternary system was re-evaluated with a thermodynamic computer program ${ }^{[32]}$ by optimizing only the ternary parameters in the fec phase, which leads to a fair agreement between the calculated and experimental boundaries of the miscibility gap, as shown in Figure 2 .

The large miscibility gap in the binary $\mathrm{Cu}-\mathrm{Fe}$ system is a result of a repulsive interaction between copper and iron atoms (the activity coefficient is larger than one). In the Cu-Ni system, the interaction between copper and nickels is also repulsive but not as strong as in case of copper and iron. A miscibility gap exists at low temperatures, but at $1000^{\circ} \mathrm{C}$, copper and nickel are mutually soluble in all compositions. In the $\mathrm{Fe}-\mathrm{Ni}$ system, the interaction between iron and nickel is slightly attractive. Because of the unequal interactions between copper and nickel vs iron and nickel, the directions of the tie-lines in the two-phase region are no parallel to the $\mathrm{Cu}-\mathrm{Fe}$ diagram axis but are directed toward the copper-rich corner. The equal activity of nickel at the interface between copper-rich and iron-rich alloys is achieved with a higher concentration of nickel on the iron side. From the direction of the tie-lines, we can predict an "up-hill" diffusion behavior of nickel in diffusion couples between certain copper-nickel alloys and pure iron. is?

In Figures 3(a) through (c), some calculated isoactivity curves for copper, iron, and nickel at $1000^{\circ} \mathrm{C}$ are presented. The activity calculations are based on the pure element $r$ ref erence state at $1000^{\circ} \mathrm{C}(1$ bar $)$. Figure 3 can be applied for 
Table III. The Calculated Tracer Diffusion Coefficients and Interdiffusion Coefficients of Copper, Iron, and Nickel at the Intersection Points Indicated by Capital Letters in Figure 4

\begin{tabular}{|c|c|c|c|c|c|c|c|c|c|c|c|c|c|c|c|c|c|}
\hline Point & $N_{\mathrm{Cu}}$ & & $N_{\mathrm{Fe}}$ & $N_{\mathrm{Ni}}$ & & $\begin{array}{c}D_{\mathrm{Cu}}^{*} \\
\left(\mathrm{~cm}^{2 / \mathrm{s}}\right) \\
\times 10^{11} \\
\end{array}$ & $\begin{array}{c}D_{\mathrm{Fe}}^{*} \\
\left(\mathrm{~cm}^{2 / \mathrm{s}}\right) \\
\times 10^{11} \\
\end{array}$ & & $\begin{array}{c}D_{\mathrm{Ni}}^{*} \\
\left(\mathrm{~cm}^{2} / \mathrm{s}\right) \\
\times 10^{11} \\
\end{array}$ & & $\begin{array}{c}D_{\mathrm{CuCu}}^{\mathrm{Ni}} \\
\left(\mathrm{cm}^{2} / \mathrm{s}\right) \\
\times 10^{11} \\
\end{array}$ & & $\begin{array}{c}D_{\mathrm{CuFe}}^{\mathrm{Ni}} \\
\left(\mathrm{cm}^{2} / \mathrm{s}\right) \\
\times 10^{11}\end{array}$ & $\therefore$ & $\begin{array}{c}D_{\mathrm{FeCu}}^{\mathrm{Ni}} \\
\left(\mathrm{cm}^{2} / \mathrm{s}\right) \\
\times 10^{11}\end{array}$ & & $\begin{array}{c}D_{\mathrm{FeFe}}^{\mathrm{Ni}} \\
\left(\mathrm{cm}^{2} / \mathrm{s}\right) \\
\times 10^{11} \\
\end{array}$ \\
\hline $\mathrm{Ba}$ & 0.84 & & 0.025 & 0.135 & & 150 & 34 & & 7 & & 20 & & 6 & & -8 & & 30 \\
\hline $\mathrm{Bb}$ & 0.84 & & 0.025 & 0.135 & . & 130 & 32 & & 10 & & 19 & & 4 & & 3 & & 32 \\
\hline $\mathrm{Ca}$ & 0.805 & & 0.075 & 0.125 & & 120 & $\therefore 33$ & & 18 & & 3 & & 0 & & $: 7$ & & 16 \\
\hline $\mathrm{Cb}$ & 0.805 & & 0.075 & 0.125 & & 210 & 38 & & 22 & & 2 & & -5 & & 14 & & 31 \\
\hline $\mathrm{D}$ & 0.81 & & 0.03 & 0.16 & & 110 & 17 & & 13 & & 16 & & 19 & & 0 & & 10 \\
\hline $\mathrm{E}$ & 0.69 & & 0.065 & 0.245 & & 46 & 17 & & 7 & & 4 & & 1 & & 4 & & 16 \\
\hline$F$ & 0.66 & ; & 0.095 & 0.245 & & 23 & $1 \div \quad 17$ & & 7 & & 1 & & -1 & & 6 & & 16 \\
\hline $4:$ & 0.42 & & 0.16 & 0.42 & & 13 & $\geqslant 4$ & & 3 & & 3 & & 4 & & 2 & $\therefore$ & 5 \\
\hline $\mathrm{H}$ & 0.195 & & 0.245 & 0.56 & & 5.2 & 1.8 & & 3.4 & & 2 & & 1.5 & & 1 & & 3 \\
\hline I & 0.205 & & 0.34 & 0.455 & & 3.0 & 3.1 & & 4.1 & & 2 & & 1.5 & & 0.5 & & 1.5 \\
\hline $\mathrm{J}$ & 0.085 & & 0.445 & 0.47 & & 2.5 & $\approx \quad 2.2$ & & 3.4 & & -1.6 & & 0.4 & & -0.3 & & 0.9 \\
\hline $\mathrm{Ka}$ & 0.185 & & 0.505 & 0.31 & & 1.1 & $\quad 1.1$ & & 0.9 & & 0.7 & & 0.3 & $w$ & 0.5 & - & 11 \\
\hline $\mathrm{Kb}$ & 0.20 & & 0.50 & 0.30 & & 2.0 & 5.2 & 3 & 1.4 & & 0.8 & & 0.3 & & 0.6 & & 13 \\
\hline $\mathrm{L}$ & 0.14 & & 0.52 & 0.34 & & $1.4^{4}$ & a $\quad 2.8$ & & 0.2 & & 0.6 & & 0 & 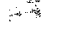 & 0.5 & & 1.2 \\
\hline $\bar{M}$ & 0.10 & . & 0.53 & 0.37 & 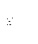 & 1.0 & 0.9 & & 0.4 & & 0.6 & & 0.1 & & 0.2 & & 0.7 \\
\hline $\mathrm{N}$ & 0.06 & & 0.53 & 0.41 & & 0.8 & 0.8 & & 0.5 & & 0.5 & & 0.05 & & 0.2 & & 0.7 \\
\hline $\mathrm{Oa}$ & 0.06 & & 0.77 & 0.17 & & 0.8 & 2.8 & & 0.3 & & 0.4 & & 0.04 & & 0.04 & & 0.2 \\
\hline $\mathrm{Ob}$ & 0.06 & & 0.77 & 0.17 & & 0.7 & 2.5 & $:$ & 0.2 & & 0.4 & & -0.03 & & -0.1 & & 0.4 \\
\hline$P$ & 0.055 & & 0.76 & 0.185 & 3 & 0.6 & 1.3 & & 0.2 & & 0.4 & & 0.01 & & 0.02 & & 0.3 \\
\hline$Q$ & 0.045 & . & 0.755 & 0.20 & $\ldots$ & 0.5 & 0.4 & & 0.2 & & 0.4 & & 0.02 & & 0.06 & & 0.2 \\
\hline
\end{tabular}

used to obtain the correct interfacial composition when extrapolating the concentration profiles to the interface.

The direction of the tie-lines in the two-phase area strongly affects the course of the diffusion path followed inside the single-phase area before reaching the two-phase area. Which tie-line is chosen is of course also dependent on the kinetics. The shapes of the diffusion paths outside the miscibility gap resemble those touching the two-phase region. When the diffusion path in the single phase runs very close to the critical point of the miscibility gap, the intrinsic fluxes actually converge to zero because the diffusion path runs almost parallel to the isoactivity lines. In the diffusion profile, this part has a very steep concentration gradient. This behavior greatly helps qualitative predictions of diffusion paths and penetration curves.

\section{B. Calculated Tracer Diffusion Coefficients}

Using Eq. [8] and the method described in Section II, the three tracer diffusion coefficients have been calculated at the intersection points shown in Figure 4. The results of these calculations are presented in-Table III and graphically in Figures 5(a) through (c), where the tracer diffusion coefficients of copper, iron, and nickel are plotted as a function of the atomic fraction of copper (circles). Some data points in the graphs have been calculated in cases where the chemical potential gradient of copper is equal to zero. Estimated average uncertainties for the tracer diffusion coefficients and interdiffusion coefficients are \pm 50 and \pm 100 pct, respectively (Section D).

The results show clearly the generally ignored concentration dependence of the mobilities. In the $\mathrm{Cu}-\mathrm{Fe}-\mathrm{Ni}$ system, the variation in interdiffusion, intrinsic diffusion, and tracer diffusion coefficient can be as large as 3 decades.

As a general tendency, the mobilities of each component increase strongly as the copper content increases. The difference in the mobilities in high-copper and low-copper al- loys is roughly 3 decades. The mobility values are actually dependent on two concentration variables. This can be seen in the scattering of data points in Figure 5 with low-copper concentrations: The higher values are from intersection points with higher nickel content, and as the iron content increases, the tracer diffision coefficients of all three components deçrease.

Some trácer diffusion data found in the literature for binary $\mathrm{Cu}-\mathrm{Ni}$ and $\mathrm{Fe}-\mathrm{Ni}$ systems $\mathrm{s}^{[3]}$ at $1000^{\circ} \mathrm{C}$ are shown in Figures 5 (a) through (c) as triangles. Good consistency with the calculated values was found. According to the data, copper is the most mobile component in copper-rich alloys followed by iron and nickel. In iron-rich alloys, iron is about as mobile as copper with nickel being again the slowest. In copper-rich alloys, the diffusion is about 2 decades faster than in nickel rich and 2 to 3 decades faster than in iron-rich alloys This is observed also in experimental diffision profiles where, at Fe-rich compositions, the concentration gradients are steep, and therefore, the extent of this part of the diffusion zone is small.

At some points $(\mathrm{B}, \mathrm{C}, \mathrm{K}$, and $\mathrm{O})$, the calculations were carried out using the profile of the diffusion couple Fe $v s$ $85 \mathrm{Cu}-15 \mathrm{Ni}$ with two different annealing times. The calculated tracer diffusion coefficients seem to be less sensitive to experimental deviations than the interdiffusion coeffcients and therefore should be preferred.

\section{Predictions of Diffusion Paths in Ternary Solid-State Diffusion Couples}

If one knows the mobilities as a function of composition as well as the thermodynamic description, it is possible to calculate the entire diffusion path if there is a sophisticated program available, such as that in Reference 9. For many applications, however, it is enough to have an estimation of in which direction the diffusion path will start.

The dependent intrinsic fluxes in Eq. [5] are dependent 


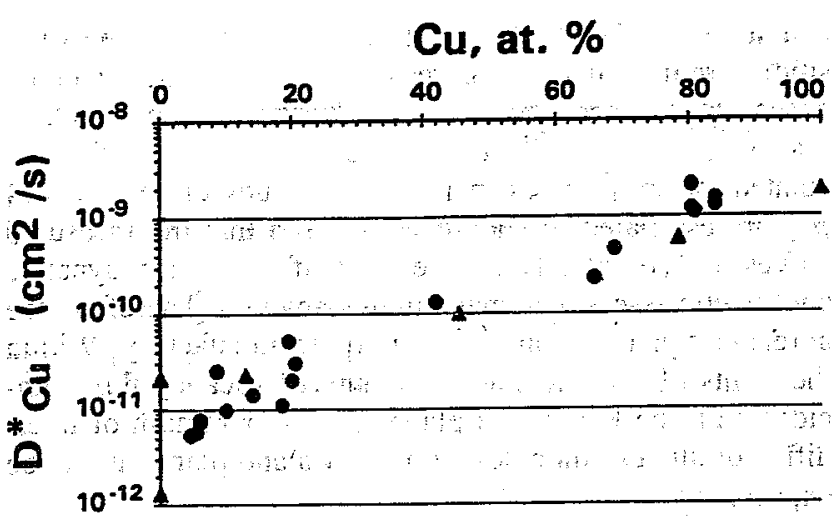

(a)

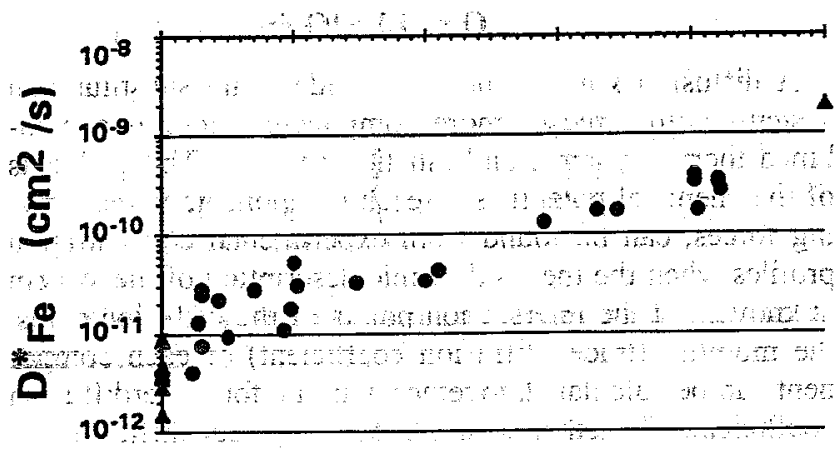

(b)

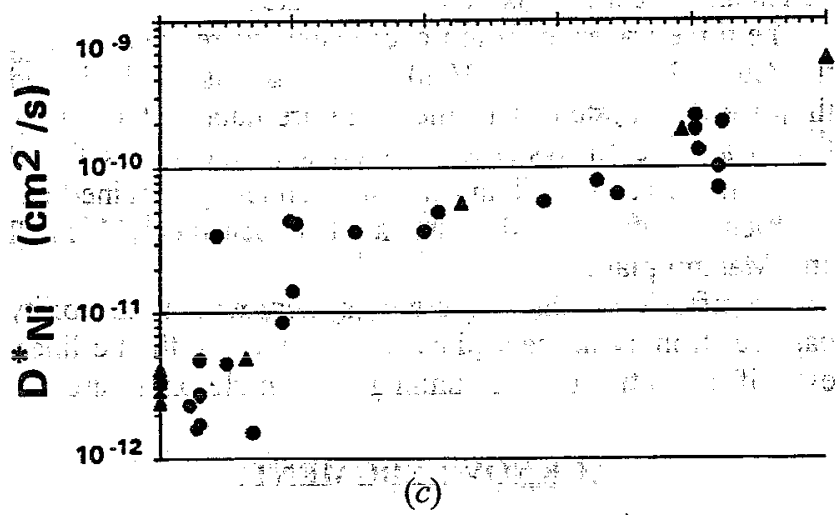

Fig. 5 The tracer diffusion coefficients of $(a)$ copper, $(b)$ iron, and $(c)$ nickel (circles)' as a function of the atomic fraction of copper calculated at the intersection points at $1000^{\circ} \mathrm{C}$. The literature data in binary $\mathrm{Cu}-\mathrm{Ni}$ and $\mathrm{Fe}-\mathrm{Ni}$ alloys ${ }^{[3]}$ have been calculated from Arrhenius plots and arepresented as triangles. The values in the binary $\mathrm{Fe}-\mathrm{Ni}$ system are shown on the axis, $N_{\mathrm{Cu}} \rightarrow 0$. The highest values are in pure nickel and the lowest in pure iron.

on the tracer diffusion coefficients and the driving forces. In binary systems, the driving force term is the same for both elements everywhere in the diffusion couple, and the intrinsic or tracer diffusion coefficients can be used directly to determine which component is diffusing fastest: In a ternary system, the driving force of each component can differ greatly. Therefore, if a component-has the greatest mobility, it does not necessarily have the largest antrinsic flux. In deed, the intrinsic fiux is the essential quantity in determining, for example, the Kirkendall movement of tol

In a thermodynamically ideal system, a diffusion path is always S-shaped. If the mobilities of the elements are constant but different, the path can be predicted using the model of van Loo.[ [ The starting direction of the diffusion
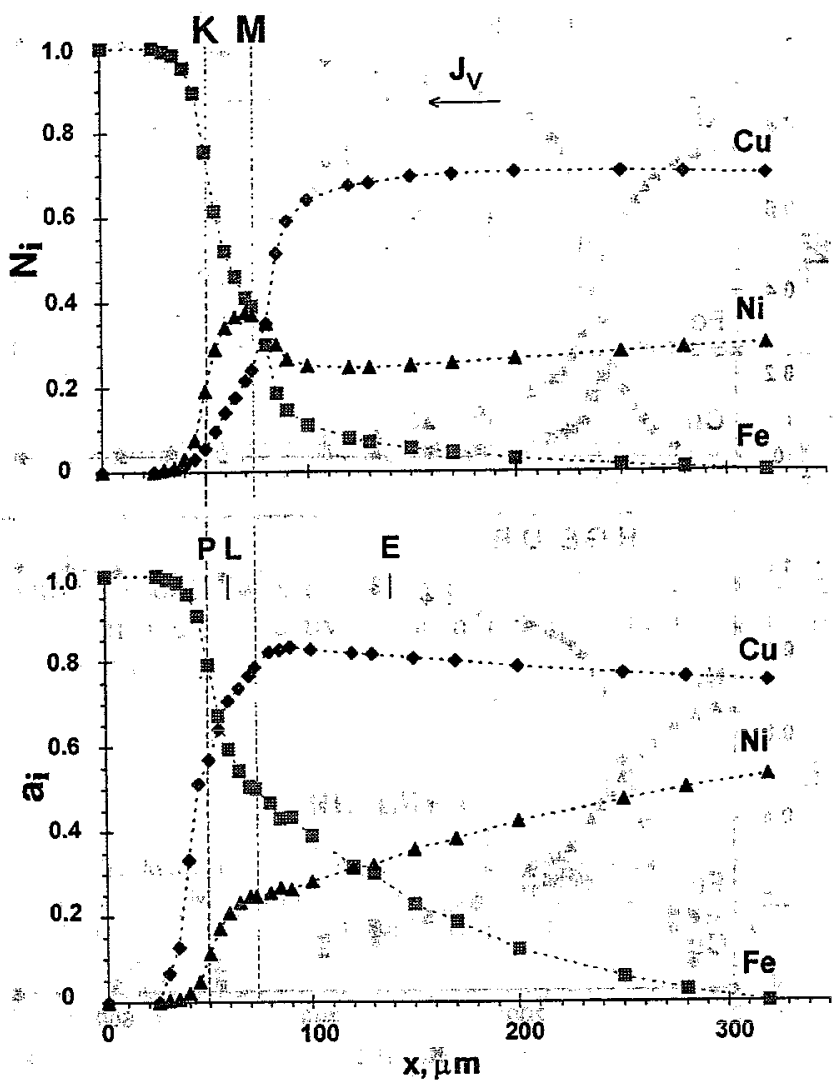

Fig. 6-The concentration profiles (above) and the activity profiles (below) in the diffusion couple $\mathrm{Fe}$ vs $70 \mathrm{Cu}-30 \mathrm{Ni}$, annealed $100 \mathrm{~h}$ at 1000 ${ }^{\circ} \mathrm{C}$. Notice the strong uphill diffusion of nickel against its ${ }^{\text {town }}$ concentration gradient. The activity curve instead goes ccorrectly" downward. In the copper-rich alloy, a "pileup" of both concentration and activity of copper is observed. The vacancy flux goes from right to left. The positions of the Kirkendall and Matano planes are indicated by the letters $\mathrm{K}$ and $\mathrm{M}$.

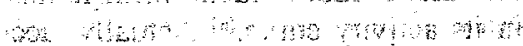

litively be estimated without any colculation path can qualitatively be estimated without any calculation. If for instance, in a couple $A B$ ys $C$ the mobilities are in the sequence $D_{A}>D_{B}>D_{C}$, then the diffusion path has to start from $A B$ in the $B$-richer ditection and from end member $C$ in the $A$-richer direction This fixes, in principal, the S-shaped diffusion path.

If the interdiffusion coefficients are constant; a prediction method based on the direction of the major and minor eigenvectors can be used 1734 As far as the nondeality in the system increases and/or the differences in mobilities decrease, the driving force term in $\mathrm{Eq}$ [5] becomes more im-

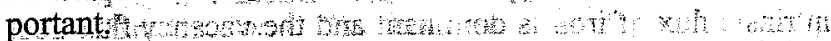

The prediction is then more intricate, as will be shown by an analysis of two diffusion couples taken from the $\mathrm{Cu}$ Fe-Ni system In Figure 6 , the eoncentration and the cor responding converted activity profiles of the diffusion couple $\mathrm{Fe}$ ys $70 \mathrm{Cu}-30 \mathrm{Ni}$ are presented The concentration and activity profiles of the diffusion couple $75 \mathrm{Ni}-25 \mathrm{Fe}$ vs Cu are shown in Figure 7 , In Figure 6 , the concentration and activity of copper in the $70 \mathrm{Cu}-30 \mathrm{Ni}$ alloy are increased when compared to the values in the terminal compositions. The same behavior is found for iron in the $75 \mathrm{Ni}-25 \mathrm{Fe}$ alloy in Figure 7 . In both cases, the diffision path from the alloy starts in the direction of lower nickel content (Figuret4). So, in locations on a diffusion couple where two compos nents are diffusing away from an alloy, the component with 

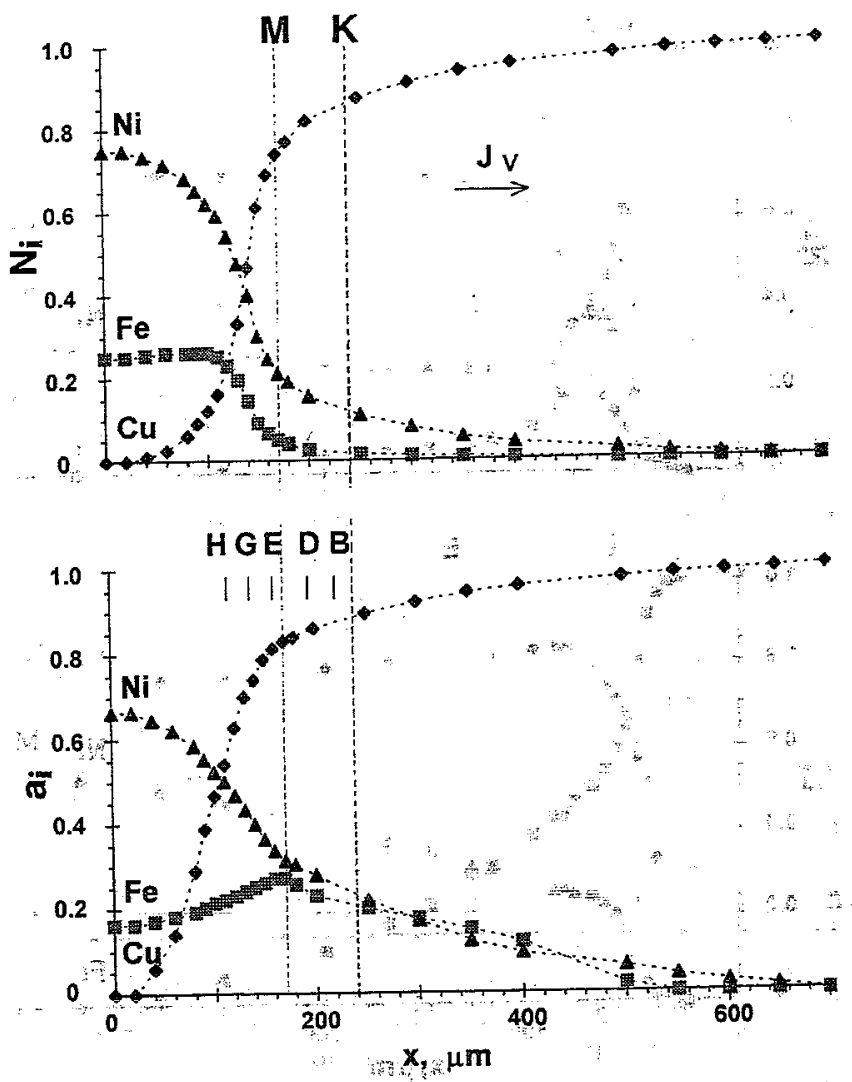

Fig. 7-The concentration profiles (above) and the activity profiles (below) in the diffusion couple $75 \mathrm{Ni}-25 \mathrm{Fe}$ vs $\mathrm{Cu}$, annealed $196 \mathrm{~h}$ at 1000 ${ }^{\circ} \mathrm{C}$ A pileup of iron eoncentration and activity is found. The direction of the vacancy fux is from left to right. The positions of the Kirkendall and Matano planes are indicated by the letters $\mathrm{K}$ and $\mathrm{M}$.

the smaller independent intrinsic flux can form a maximum in its activity curve ${ }^{[6]}$ Actually, according to the mobility data, nickel is always the slowest diffusing component, and so, using the predictions for a thermodynamically ideal system, the diffusion path should start, in both cases from the initiallalloys in a Nitriche direction. The opposite is true, as seen from Figuie 4 , showing that thermodynamic inter-

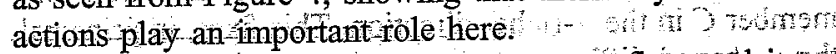

The dependent intrinsic fluxes, vacancy flux, and inter diffusion fluxes given in Table IV are calculated at the points shown in Figures 6 and 7 , corresponding to the in tersection points described in Table HI, ùsing Eqs. [5], [9]; and $[10]$

In the diffusion couple $\mathrm{Fe} w \bar{s} 70 \mathrm{Cu}-30 \mathrm{Ni}$, the dependent intrinsic flux of iron is dominant and the vacancy fiux goes from the $70 \mathrm{Cu}-30 \mathrm{Ni}$ alloy (right) toward pure iron (left): Because only a small amount of exper diffuses into the iron; -only a small ameunt of copper can leave the Cu-Ni alloy, which causes an increase in copper concentration. Because of the strong repulsive interaction between ron and copper, the substitution of nickel by iron increases the activity of copper, causing the maximum in the activity profile of copper

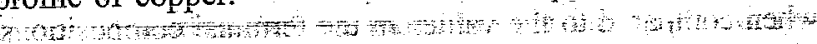
D. Marker Experiments

The marker movement was studied by using small particles $(0.5 \mu \mathrm{m})$ of hafnium dioxide and aluminum oxide as inert markers between the initial materials. For the diffusion couples $\mathrm{Fe}$ vs $70 \mathrm{Cu}-30 \mathrm{Ni}$ and $75 \mathrm{Ni}-25 \mathrm{Fe} v s \mathrm{Cu}$, their positions are indicated in Figures 6 and 7. The experimentally observed distances between the Kirkendall and Matano planes were 23 and $70 \mu \mathrm{m}$, respectively. Based on the calculated vacancy fluxes in Eq. [11], values of 18 and 113 $\mu \mathrm{m}$ are estimated. It should be stressed that the measured values are completely independent of the thermodynamic and kinetic assessment made in this analysis. Therefore, the agreement can be considered as quite satisfactory. Within the limits of accuracy, an extremum of vacancy flux coin cides with the Kirkendall plane and an extremum of inter diffusion fluxes coincides with the Matano plane, as can be expected. ${ }^{[6]}$

\section{CONCLUSIONS}

A diffusion kinetic study in nonideal and substitutional systems with three or more components requires a combined thermodynamic and kinetic approach. The gradients of the chemical potentials of each component, as real driving forces, can be found from experimental concentration profiles when the thermodynamic description of the system is known. At the intersection points of the diffusion paths, the mobility (tracer diffusion coefficient) of each component can be calculated, together with the four interdiffusion coefficients. Together with the data of tracer diffusion coefficients and their concentration dependence, the intrinsic fluxes and vacancy flux can be calculated.

The three tracer diffusion coefficients were calculated in the $\mathrm{Cu}-\mathrm{Fe}-\mathrm{Ni}$ system at $1000{ }^{\circ} \mathrm{C}$ using this method, and they were consistent with the literature data in the binary $\mathrm{Cu}-\mathrm{Ni}$ and $\mathrm{Fe}-\mathrm{Ni}$ systems. A good agreement was found between the calculated and the independently obtained experimental values for the distance between the Kirkendall and Matano planes.

The diffusion paths in a ternary-system with a miscibility gap are strongly influenced by the direction of the tie-lines even if the entire path is running in a single-phase area?

\section{ACKNOWLEDGMENTS}

We wish to thank Mr, P. Broers for designing and op erating the vacuum furnaces which play an important role in this research project. This work was financially supported by the Academy of Finland.

\section{APPENDIX}

In the following, a relationship between the independent (with prime) and dependent intrinsic variables in the ther modynamically ideal case is presented: In a binary system? no difference exists between these variables, and therefore, there is no reason to introduce different definitions for the intrinsic flux. In a ternary system, however, the sum of the independent atomic fractions can differ from unity $\left(\Sigma N^{N}\right.$ th 1) if the independent intrinsic fluxes are used to describe the diffusion behavior [6] This corresponds with an extra expansion or shrinkage of the couple. For the atomic fract tion, the following relation can be written;

$\quad N_{i}=\frac{N_{i}}{\sum_{i=1}^{3} N_{j}}$ 
Table IV. The Calculated Intrinsic Diffusion, Vacancy, and Interdiffusion Fluxes in Diffusion Couples Fe $v s 70 \mathrm{Cu}-30 \mathrm{Ni}$ (Figure 6) and 75Ni-25Fe vs $\mathrm{Cu}$ (Figure 7)

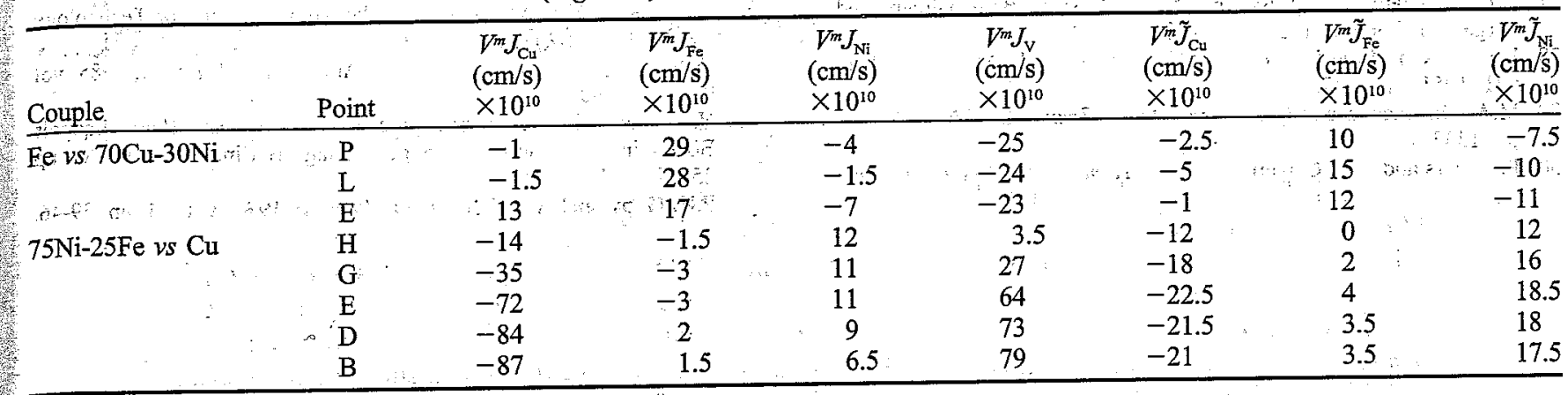

which leads to

$$
\frac{\partial N_{i}}{\partial N_{i}^{\prime}}=\frac{1}{\sum_{j=1}^{3} N_{j}^{r}}\left(1-N_{i} \frac{\partial\left(\sum_{j=1}^{3} N_{j}\right)}{\partial N_{i}^{r}}\right)
$$

The relation between the distance variables $x$ and $x^{\prime}$ can be -expressed as

$$
x=x^{i}+\int_{-\infty}^{x^{\prime \prime}}\left(\sum_{j=1}^{3} N_{j}-1\right) d x
$$

and

$$
\frac{d x}{d x^{\prime}}=\sum_{j=1}^{3} N_{j}^{\prime}
$$

A relation between the gradients of atomic fraction can be derived from the chain rule

$$
\frac{\partial N_{i}}{\partial x}=\left(\frac{\partial N_{i}}{\partial N_{i}^{\prime}}\right)\left(\frac{\partial x^{\prime}}{\partial x}\right)\left(\frac{\partial N_{i}^{\prime}}{\partial x^{\prime}}\right)
$$

which leads to

$$
\frac{\partial N_{i}}{\partial x}=\frac{1}{\left(\sum_{j=1}^{3} N_{j}\right)^{2}}\left(1-N_{i} \frac{\partial\left(\sum_{j=1}^{3} N_{j}^{\prime}\right)}{\partial N_{i}^{\prime}}\right)\left(\frac{\partial N_{i}^{\prime}}{\partial x^{\prime}}\right)
$$

If we assume that $D_{i}^{*}\left(N_{i}\right)=D_{i}^{*}\left(N_{i}^{\eta}\right)$, a relation between the dependent and independent intrinsic fluxes $J_{i}$ and $J_{i}$ respectively, can be expressed as

$$
J_{i}=-\frac{D_{i}^{*}}{V^{m}} \frac{\partial N_{i}}{\partial x}=J_{i} \frac{1}{\left(\sum_{j=1}^{3} N_{j}^{r^{2}}\right)^{2}}\left(1-N_{i} \frac{\partial\left(\sum_{j=1}^{3} N_{j}\right)}{\partial N_{i}}\right)
$$

These two fluxes have a different direction if

$$
\frac{-\partial\left(\sum_{j=1}^{3} N_{j}\right)}{\partial x^{\prime}}>\frac{1}{N_{i}} \frac{\partial N_{i}}{\partial x^{\prime}}
$$

and both gradients have the same sign. This means that $J_{i}$ has a different sign at either side of an extremum in the activity profile, whereas $J_{i}$ always has the same direction, $v i z$. from the high-activity end member to the low-activity end member.

\section{REFERENCES}

1. J.S. Kirkaldy and D.J. Young: Diffusion in the Condensed State, The Institute of Metals, London, 1987, pp. 172-272.

2. T.O. Ziebold and R.E. Ogilvie: Trans. TMS-AIME, 1967, vol. 239, pp. 942-53.

3. M.A. Dayananda, 户̀.F. Kirch, and R.E. Grace: Trans. TMS-AIME, 1968, vol. 242, pp. 885-90.

4. H. Fujita and L.J. Gosting: J. Am. Chem. Soc., 1956, vol. 78, pp. 1099-1106.

5. J.S. Kirkaldy: Can. J. Phys., 1958, vol. 36, pp. 899-906.

6. F.J.J. van Loo, G.F. Bastin, and J.W.G.A. Vrolijk: Metall. Trans. A., 1987, vol. $18 \mathrm{~A}$, pp. $801-09$.

7. M.S. Thompson and J.E. Morral: Acta Metall., 1986, vol. 34, pp. 33946.

8. J.E. Morral and M.S. Thompson: Diffusion Analysis and Applications, A.D. Romig, $\mathrm{J}_{\mathrm{r}}$ and M.A. Dayananda, eds., TMS, Warrendale, PA, 1989, pp. 35-49.

9. J.-O. Andersson, L. Höglund, B. Jönsson, and J. Ågren: Fundamentals and Applications of Ternary Diffusion, G.R. Purdy, ed., Pergamon Press, New York, NY, 1990, pp. 153-63.

10. H. Sato: Diffusion Analysis and Applications, A.D. Romig, Jr. and M.A. Dayananda, eds., TMS, Warrendale, PA, 1989, pp. 19-23.

11. C.W. Kim and M.A. Dayananda: Metall. Trans. A, 1983, vol 14A; pp. 857-64. C.W. Kim and M.A. Dayananda: Metall Trans: A., 1984, vol. $15 \mathrm{~A}$, pp. $649-59$.

12. J.S. Kirkaldy and L.C. Brown: Can. Met. Q., 1963, vol. 2, pp. 89117.

13. Robert A. Rapp; Andre Ezis, and Gregory J. Yurek Metall. Trans., 1973, vol. 4, pp. 1283-92.

14. F.J.J. van Loo, J.A. van Beek, G.F. Bastin, and R. Metselaar: Diffusion in Solids: Recent Developments, Proc. TMS-AIME Fall Meeting, Detroit, MI, 1984, M.A. Dayananda and G.E. Murch, eds., TMS-AIME, Warrendale, PA, 1984, pp. 231-59.

15. J.S. Kirkaldy: Can. J. Phys, 1957, vol. 35, pp. 435-40.

16. M.A. Dayananda: Diffusion in Solids: Recent Developments, Proc TMS-AIME Fall Meeting, Detroit, MI, 1984, M.A. Dayananda and G.E. Murch, eds, TMS-AIME, Warrendale, PA, 1984, pp. 195-230.

17. M.A. Dayananda: Defect Diffusion Forum, 1992, vol 83, pp. 73-86.

18. J.E. Lane and J.S. Kirkaldy: Can. J. Phys., 1964, vol. 42, pp. 1643-57.

19. J.P. Sabatier and A. Vignes: Mém. Sci. Rev. Métall., 1967, vol: 64, pp. 225-40.

20. T. Takahashi, M. Kato, Y. Minamino, and T. Yamane Jpn. Inst. Met., 1986 , vol 50 , pp. $243-49$.

21. M.A. Dayananda: Trans. TMS-AIME, 1968, vol. 242, pp. 1369-72.

22. J.D. Whittenberger and M:A. Dayananda: Metall: Trans., 1970, vol. 1 , pp: 3301-08.

23. P.T. Carlson and M.A. Dayananda: Metall. Trans. A, 1975, vol.6A, pp. $1245-52$.

24. M. Yokota, R. Harada, and H. Mitani: Trans. Jpn. Inst. Met., 1980 , vol. 21 , pp. $573-79$.

25. L. Onsager: Ann. N.Y. Acad. Sci.; 1945, vol. 46, pp. 241-65. 
26. J.. Bardeen and C. Herring: Atom Movements, J.H. Hollomon, ed., ASM, Cleveland, $\mathrm{OH}, 1951$, pp. 87-111.

27. A.D. LeClaire: Progress in Metal Physics, B. Chalmers, ed. Pergamon, London, 1953, vol. 4, pp. 265-332.

28. L.S. Darken: Atom Movements, J.H. Hollomon, ed., ASM, Cleveland, OH, 1951, pp. 1-17.

29. M.A. Dayananda and C.W. Kim. Metall. Trans. A, 1979, vol. 10A, i. pp. 1333-39.

30. P. Villars and L.D. Calvert: Pearson's Handbook of Crystallographic

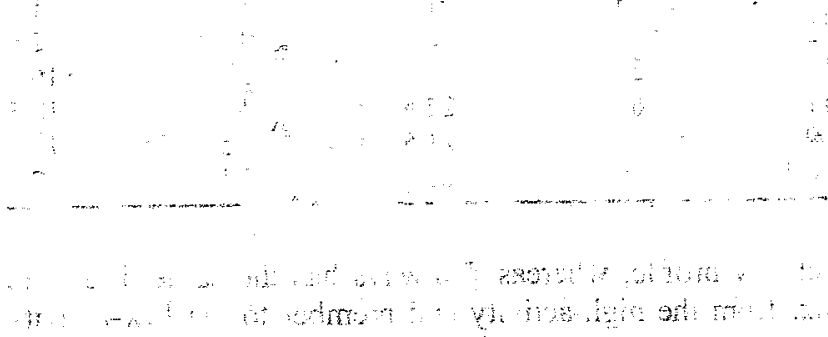

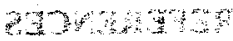

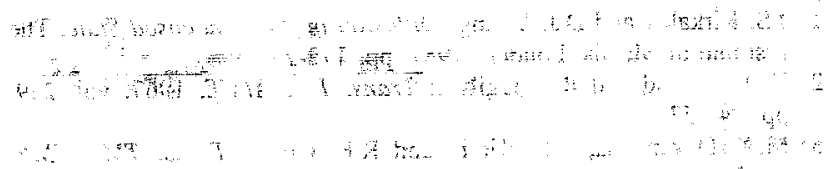

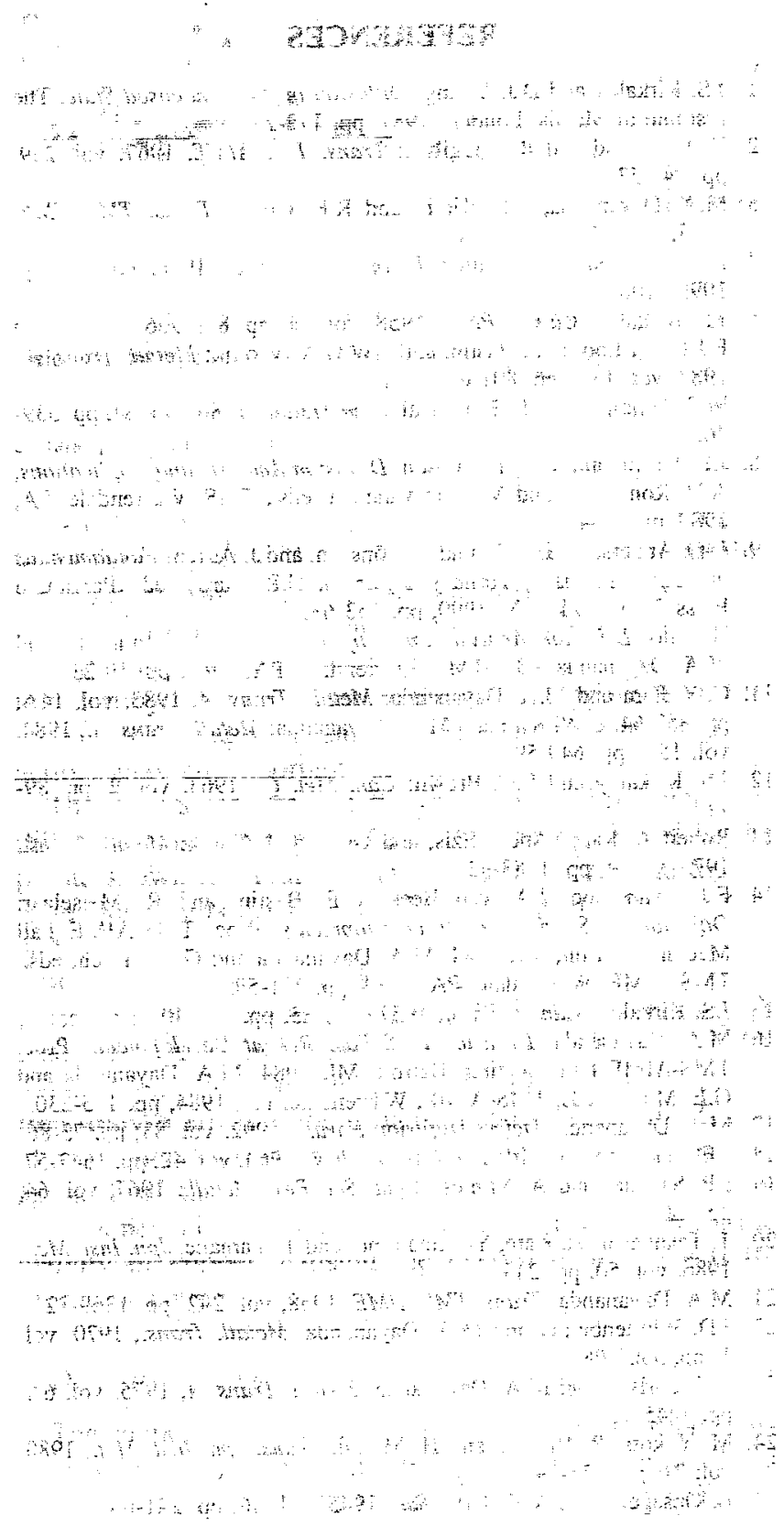

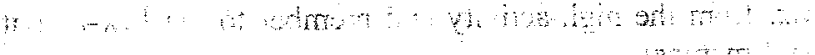

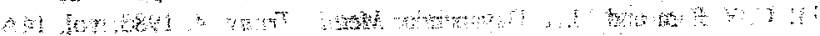

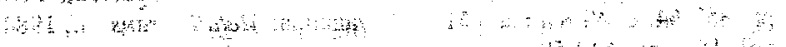
tor

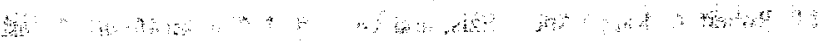

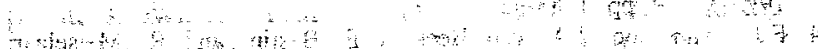

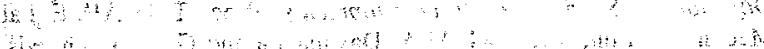
istatis

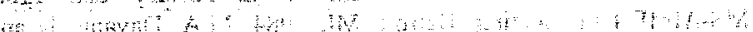
-

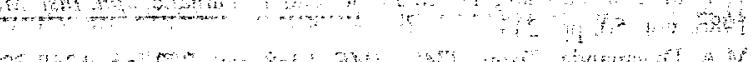

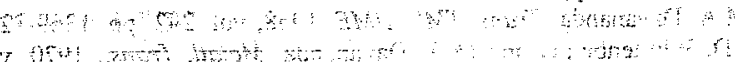
$4 \sin 2, x$
Data for Intermetallic Phases, ASM, Metals Park, OH, '1985 pp. 1929-30.

31. A. Jansson: TRITA-MAC-0340, The Royal Institute of Technology, Stockhoim, Apr. 1987 pp. 1-14.

32. B. Sundman, B. Jansson, and J.-O. Anderson: CALPHAD, 1985, vol. 9. $\mathrm{pp} .153-90$.

33. H. Meher (Ed): Diffusion in-Solid Metals and Alloys LandoltBörnstein, New Series, Springer-Verlag, Berlin, 1990, v. 26, pp 258-63.

34. P.K. Gupta and A.R. Cooper, Jr.: Physica, 1971, vol. 54, pp. 39-46.

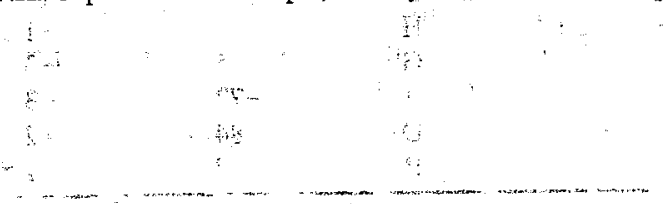

